\title{
Association of folate intake with the occurrence of depressive episodes in middle-aged French men and women
}

\author{
Pierre Astorg ${ }^{1 *}$, Aline Couthouis ${ }^{2}$, Geneviève Potier de Courcy ${ }^{3}$, Sandrine Bertrais ${ }^{3}$, Nathalie Arnault ${ }^{3}$, \\ Pierre Meneton ${ }^{4}$, Pilar Galan ${ }^{3}$ and Serge Hercberg ${ }^{3}$ \\ ${ }^{1}$ Unité Nutrition et Régulation Lipidique des Fonctions Cérébrales (NuRéLiCe), INRA, Centre de Recherche de Jouy-en-Josas, \\ France \\ ${ }^{2}$ Caisse Primaire d'Assurance Maladie de Paris, France \\ ${ }^{3}$ UMR Inserm 557/INRA/Cnam/Paris 13 Epidémiologie Nutritionnelle, Centre de Recherche en Nutrition Humaine d'Ile-de-France, \\ Université Paris 13, Bobigny, France \\ ${ }^{4}$ INSERM U367, Département de Santé Publique et d'Informatique Médicale, Faculté de Médecine Broussais, Hôtel Dieu, Paris, \\ France \\ (Received 14 March 2007 - Revised 27 September 2007 - Accepted 28 September 2007 - First published online 6 December 2007)
}

\begin{abstract}
A low folate intake or a low folate status have been found to be associated with a higher frequency of depression in populations, but the existence and the direction of a causal link between folate intake or status and depression is still uncertain. The aim of this study was to seek the relation between the habitual folate intake in middle-aged men and women and the occurrence of depressive episodes. In a subsample of 1864 subjects ( 809 men and 1055 women) from the French SU.VI.MAX cohort, dietary habits have been measured at the beginning of the follow-up (six $24 \mathrm{~h}$ records) and declarations of antidepressant prescription, taken as markers of depressive episodes, have been recorded during the 8-year follow-up. No significant association was observed between folate intake and the risk of any depressive episode or of a single depressive episode during the follow-up, in both men and women. In contrast, the risk of experiencing recurrent depressive episodes (two or more) during the follow-up was strongly reduced in men with high folate intake (OR 0.25 (95\% CI 0.06, 0.98) for the highest tertile $v$. the lowest, $P$ for trend 0.046). This association was not observed in women. These results suggest that a low folate intake may increase the risk of recurrent depression in men.
\end{abstract}

Folate: Depression: Cohort studies

An insufficient folate intake is common in many populations, and is a strong risk factor of neural tube defects and other congenital anomalies when it occurs in pregnant women ${ }^{(1)}$, which has led to mandatory fortification policies in several countries $^{(1)}$. In adult or elderly people, a low folate intake has also been associated with an increased risk of CVD and of stroke $^{(1,2)}$, as well as of Alzheimer's disease and of vascular dementias ${ }^{(2,3)}$. Due to its involvement in one-carbon metabolism, folate appears to have a fundamental role in brain function at all ages ${ }^{(3)}$. Depression, one of the most widespread psychiatric disorders in the human population, is one of the neuropsychiatric symptoms of folate deficiency in human subjects ${ }^{(3,4)}$. Moreover, a low folate status has been often observed in depressive patients, and adjunct treatment with folate improves the patients' response to antidepressants ${ }^{(4,5)}$. In population observational studies, a low folate intake or a low folate status have been found to be associated with a higher risk of depression, which suggests that an increased folate intake could reduce depression risk in the general population $^{(6-11)}$. However, only few of these studies have a prospective design, from which one could infer a causal link between folate intake or status and the subsequent onset of depression. In the present study, we have used the data of the French SU.VI.MAX cohort to look for the association between the level of folate intake, measured at the beginning of the follow-up, and the onset of depressive episode during the follow-up.

\section{Subjects and methods}

The SU.VI.MAX study

The SU.VI.MAX study is a randomised, double-blind, placebocontrolled primary prevention trial designed to test the effects of daily supplementation with a mixture of vitamin $\mathrm{C}$, vitamin $\mathrm{E}, \beta$-carotene, zinc and selenium on the incidence of ischaemic heart diseases and of cancers in a population of adult men and women $^{(12)}$. Another objective of the study was to evaluate food consumption in a national sample of middle-aged

Abbreviation: Nad, number of antidepressant prescriptions

* Corresponding author: P. Astorg, fax +331346523 11, email pierre.astorg@jouy.inra.fr 
subjects from all over France. The cohort consisted of 13017 subjects (5141 men and 7876 women) who were included in 1994-1995 with a planned follow-up of 8 years. Men were aged 45-60 and women 35-60 at enrolment. Details on study design, recruitment, and baseline characteristics of the subjects have been reported previously ${ }^{(12)}$. All subjects gave their informed written consent to the study. The study was approved by ad hoc ethical committees, i.e. the 'Comité consultatif de protection des personnes dans la recherche biomédicale' (CCPPRB no. 706, Cochin Hospital, Paris, France), and the 'Commission nationale de l'informatique et des libertés' (CNIL no. 334641).

\section{Definition of controls and cases}

In the baseline questionnaire, the subjects had to mention if they had a history of depressive episodes. At baseline and every month during the follow-up, the subjects had to report health/ disease events, in particular each consultation with a health professional, with the mention of the drugs prescribed. Among the subjects for whom complete prescription data were available for the whole study follow-up, including at baseline ( 8 years, until 2002), we selected: all subjects having declared at least one antidepressant or lithium prescription during the follow-up (cases, $n$ 664); all subjects with no declarations of antidepressant or lithium prescription and with no depression history (controls, $n$ 3084), i.e. a total of 3748 subjects. Within cases, subjects having declared one or more than one (two to five) antidepressant or lithium prescriptions during follow-up were distinguished. We used antidepressant or lithium prescriptions as markers of depressive episodes, antidepressants being defined as drugs classed as antidepressants in the 1994-2002 editions of the Vidal French drug repertory.

\section{Dietary assessment}

At inclusion and every 2 months until the end of the study, subjects were asked to complete a $24 \mathrm{~h}$ dietary record questionnaire, i.e. a total of six questionnaires per year. A large choice of foods and drinks (about 900 items) was displayed for each of three meals (breakfast, lunch and dinner) and of four other foodintake occurrences. For each food or drink mentioned, the subjects were asked to indicate the portion size consumed. They were helped by an instruction manual given to them at the start of the study, including photographs of three portion sizes of 236 foods and drinks, and the use of which has been validated. Six records had been shown to be sufficient to estimate the individual intakes of macronutrients with a good accuracy ${ }^{(13)}$. Among the 3748 subjects (1509 men and 2239 women) initially selected, we retained those having reported at least six $24 \mathrm{~h}$ dietary records within a period of 2 years from inclusion: 1864 subjects, 809 men and 1055 women, on whom this study is based. Other details on questionnaires have been published previously $^{(12,14)}$. A food composition table adapted to the analysis of the dietary data collected in the SU.VI.MAX study was developed on the basis of existing data ${ }^{(15)}$.

\section{Statistical analyses}

Statistical analyses were performed using SAS software (SAS Institute, Cary, NC, USA). Frequencies were compared by the Fisher's exact test. Means were compared using the $t$ test.
Logistic regression was used to calculate OR for the 2 nd and 3rd tertiles of folate intake relative to the first one, their $95 \%$ $\mathrm{CI}$ and the test of linear trend, separately for men and women. Compared to linear regression, which could also be used in this design, logistic regression is better adapted to detect always possible non-linear relations, and can also test for linearity. In addition, it has the advantage of yielding OR estimates, representing variations of the risk according to the independent (nutritional) variable. Age, intervention group (intervention or placebo), marital status (single or living in couple), education level (three levels), socio-professional category (five categories) and total energy intake were included in the model as adjustment variables. Since depression history is a determinant of later depression, we also carried out the same analyses keeping only the cases having declared no depression history: sixty-one men instead of seventy-eight (78\%) and 192 women instead of 226 ( $85 \%$ ) (control subjects were initially selected with no depression history).

\section{Results}

Some characteristics of cases and controls are shown in Table 1, where cases with either one or more than one antidepressant prescription (Nad) during follow-up are distinguished. Women having declared one antidepressant prescription $(\mathrm{Nad}=1)$ were living alone more often than controls $(P=0.003)$, but there was no significant difference in marital status between cases and controls among men. Men having declared two or more antidepressant prescriptions $(\mathrm{Nad}>1)$ had a decreased folate intake $(P=0 \cdot 0005)$. Within each sex, age at baseline, education level, total energy intake and alcohol intake did not differ between cases and controls. Table 2 presents the OR of antidepressant prescription according to tertiles of folate intake, adjusted for age, intervention group, education level, marital status, socio-professional category, and total energy intake (OR1). No significant association was observed between folate intake and the risk of any depressive episode $(\mathrm{Nad} \geq 1)$ or of a single depressive episode $(\mathrm{Nad}=1)$ during the followup, in both men and women. In contrast, the risk of recurrent (two or more) depressive episodes during follow-up (Nad $>1)$ was significantly and strongly decreased in men with increasing folate intake, with a $75 \%$ reduced risk in the 3rd tertile of intake relative to the first one (OR1 $=0.25$ (95\% CI 0.06, 0.98), $P$ for trend 0.046). When the analysis was restricted to the cases with no depression history, the OR values (OR2) were essentially unaltered, but the association found in men between recurrent depression and folate intake was no longer significant $(\mathrm{OR} 2=0.24(95 \%$ CI $0.05,1.25)$ for the 3rd tertile $v$. the $1 \mathrm{st}$ one, $P$ for trend $=0 \cdot 10$ ). This association between folate intake and recurrent depression was not observed in women.

\section{Discussion}

In this study, we have found that a low folate intake was associated with an increased risk of recurrent depression, but not of single-episode depression, in men. This association was not found in women. The strengths of this study are the detailed dietary assessment at the beginning of the followup, and the recording of depressive episodes during the 8-year follow-up, resulting in a quasi-prospective design. The use of six $24 \mathrm{~h}$ records is an adapted method for the 
Table 1. Characteristics of controls and cases

\begin{tabular}{|c|c|c|c|c|c|c|}
\hline & \multicolumn{2}{|c|}{ Controls } & \multicolumn{2}{|c|}{$\mathrm{Nad}=1$} & \multicolumn{2}{|c|}{$\mathrm{Nad}>1$} \\
\hline & Mean & SD & Mean & SD & Mean & SD \\
\hline \multicolumn{7}{|l|}{ Men (total $n$ 809) } \\
\hline$n$ & \multicolumn{2}{|c|}{731} & \multicolumn{2}{|c|}{47} & \multicolumn{2}{|c|}{31} \\
\hline Age at baseline (years) & $52 \cdot 0$ & 4.6 & 51.4 & $4 \cdot 3$ & $50 \cdot 9$ & 4.6 \\
\hline Education level (\%) & & & & & & \\
\hline Elementary & \multicolumn{2}{|c|}{$20 \cdot 3$} & \multicolumn{2}{|c|}{$21 \cdot 3$} & \multicolumn{2}{|c|}{$27 \cdot 6$} \\
\hline High school & \multicolumn{2}{|c|}{$37 \cdot 1$} & \multicolumn{2}{|c|}{$38 \cdot 3$} & \multicolumn{2}{|c|}{37.9} \\
\hline University & \multicolumn{2}{|c|}{$42 \cdot 6$} & \multicolumn{2}{|c|}{40.4} & \multicolumn{2}{|c|}{34.5} \\
\hline \multicolumn{7}{|l|}{ Marital status (\%) } \\
\hline Living alone & \multicolumn{2}{|c|}{$10 \cdot 7$} & \multicolumn{2}{|c|}{$4 \cdot 3$} & \multicolumn{2}{|c|}{$20 \cdot 7$} \\
\hline Total energy intake $(\mathrm{MJ} / \mathrm{d})$ & $10 \cdot 39$ & $2 \cdot 30$ & $10 \cdot 39$ & 2.38 & 9.71 & 2.34 \\
\hline Alcohol intake $(g / d)$ & $29 \cdot 1$ & $23 \cdot 7$ & 29.4 & $24 \cdot 4$ & 31.9 & 29.7 \\
\hline Folate intake $(\mu \mathrm{g} / \mathrm{d})$ & 342 & 94 & 350 & 109 & $282^{*}$ & 87 \\
\hline \multicolumn{7}{|l|}{ Women (total $n$ 1055) } \\
\hline$n$ & \multicolumn{2}{|c|}{829} & \multicolumn{2}{|c|}{130} & \multicolumn{2}{|c|}{96} \\
\hline Age at baseline (years) & $47 \cdot 8$ & 6.5 & $46 \cdot 7$ & $6 \cdot 0$ & $47 \cdot 2$ & $6 \cdot 6$ \\
\hline \multicolumn{7}{|l|}{ Education level (\%) } \\
\hline Elementary & \multicolumn{2}{|c|}{$18 \cdot 9$} & \multirow{2}{*}{\multicolumn{2}{|c|}{$\begin{array}{l}19 \cdot 4 \\
37 \cdot 1\end{array}$}} & \multicolumn{2}{|c|}{$18 \cdot 3$} \\
\hline High school & \multirow{2}{*}{\multicolumn{2}{|c|}{$\begin{array}{l}40 \cdot 4 \\
40 \cdot 7\end{array}$}} & & & & \\
\hline University & & & \multicolumn{2}{|c|}{43.5} & \multicolumn{2}{|c|}{$38 \cdot 7$} \\
\hline \multicolumn{7}{|l|}{ Marital status (\%) } \\
\hline Living alone & \multicolumn{2}{|c|}{$17 \cdot 5$} & & & & \\
\hline Total energy intake $(\mathrm{MJ} / \mathrm{d})$ & $7 \cdot 75$ & 1.92 & $7 \cdot 62$ & 1.98 & 7.92 & $2 \cdot 28$ \\
\hline Alcohol intake $(g / d)$ & 11.6 & 14.4 & $12 \cdot 2$ & $16 \cdot 0$ & $13 \cdot 3$ & 14.4 \\
\hline Folate intake $(\mu \mathrm{g} / \mathrm{d})$ & 289 & 85 & 286 & 93 & 297 & 114 \\
\hline
\end{tabular}

Nad, number of antidepressant prescriptions.

* Mean value was significantly different from controls ( $t$ test) $P=0.0005$.

† Mean value was significantly different from controls (Fisher's exact test) $P=0.003$.

estimation of folate intake, provided the questionnaire is sufficiently detailed. Recent works have measured individual folate intake using only two or three $24 \mathrm{~h}$ recalls ${ }^{(16-18)}$. In this study, the six $24 \mathrm{~h}$ records allow considerable reduction of the within-subject variance ${ }^{(13)}$, and the questionnaire with more than 900 items (and a recent table adapted to this questionnaire ${ }^{(15)}$ ) reasonably covers all folate sources. The six $24 \mathrm{~h}$ records method has already been used for folate intake estimation in the SU.VI.MAX study ${ }^{(19)}$. The weaknesses of this study are the selection of a sample from the initial population, a lack of power, and the 'soft' nature of the endpoint used. In our final sample, the 8-year prevalence of antidepressant prescription is $10 \%$ in men and $21 \%$ in women. These values are consistent with prevalence values of major depression in a lifetime $(11-12 \% \text { in men and } 22-25 \% \text { in women })^{(20)}$ and of antidepressant use for 1 year $(4 \%$ in men and $8 \%$ in women $)^{(21)}$ found in the French adult population. Moreover, the values in our sample have not been substantially modified by the selection of subjects with six $24 \mathrm{~h}$ dietary records (about $50 \%$ of the initial sample). Therefore, the sample selection did not appear to introduce a significant selection bias by excluding preferentially subjects having had depressive episodes. Antidepressant prescription is an imperfect proxy for depressive episodes since a significant proportion of depressed subjects does not seek treatment ${ }^{(22)}$ and thus many cases are missed. However, this proportion is expected to be lesser in the SU.VI.MAX cohort than in the general population, because the volunteers are likely to be more health-conscious ${ }^{(12,14)}$. This is still more true for the sample used, consisting of the most compliant volunteers. In a cohort not designed to detect depression, antidepressant prescription is thus a useful marker of depressive episodes. It has the advantage on cross-sectional assessment of depressive symptoms of recording depressive episodes with time, not only current depression. Moreover, the misclassification bias that unavoidably results from the use of such a proxy would always lead to weaken an existing association, not to create it or to strengthen it artificially. The association found in men with recurrent episodes was not attenuated by adjustment for marital status, education level or socio-professional category. When the analysis was restricted to the cases with no depression history, the OR value remained identical, but it was no longer significant (although the linear trend is not far from significance $(P=0 \cdot 10))$, suggesting a loss of power. With a reserve on the latter point due to the lack of significance, these results overall suggest that the association found between folate intake and recurrent depression in men was not due to confounding by these known risk factors of depression.

Among the case-control or cross-sectional studies which have looked for an association between folate intake or status and depression or depressive symptoms in adult populations, some failed to find an association ${ }^{(23,24)}$, but others found lower folate intake or status in depressed subjects ${ }^{(6-10)}$, this association being found only in women in some studies $^{(6,8)}$. A prospective study in Japanese pregnant women did not find any association between folate intake in pregnancy and the risk of post-partum depression ${ }^{(25)}$. In a cohort of Finnish men where depressive symptoms have been assessed cross-sectionally, men in the lowest tertile of folate intake had an increased risk of depression $(\mathrm{OR}=1.67$ relative to men in the highest tertile ${ }^{(10)}$. In the same cohort, men with a baseline folate intake below the median have a three times greater risk of being hospitalised for depression during the 
Table 2. Association between occurrence of depressive episodes (marked by number of antidepressant prescriptions (Nad)) during follow-up and folate intake: OR by tertiles of folate intake

\begin{tabular}{|c|c|c|c|c|c|c|c|c|c|}
\hline & \multicolumn{2}{|c|}{ 1st tertile } & \multicolumn{3}{|c|}{ 2nd tertile } & \multicolumn{3}{|c|}{ 3rd tertile } & \multirow[b]{2}{*}{$P$ for linear treno } \\
\hline & Mean & SD & Mean & SD & $95 \% \mathrm{Cl}$ & Mean & SD & $95 \% \mathrm{Cl}$ & \\
\hline Folic acid intake $(\mu \mathrm{g} / \mathrm{d})$ & 241 & 43 & 336 & 22 & & 443 & 69 & & \\
\hline Cases $(n) / N$ & \multicolumn{2}{|c|}{$32 / 269$} & \multicolumn{2}{|c|}{$25 / 270$} & & \multicolumn{2}{|c|}{$21 / 270$} & & \\
\hline OR1 & \multicolumn{2}{|c|}{1.00} & \multicolumn{2}{|c|}{0.91} & $0.47,1.73$ & \multicolumn{2}{|c|}{0.81} & $0.39,1.70$ & 0.58 \\
\hline OR2 & \multicolumn{2}{|c|}{1.00} & \multicolumn{2}{|c|}{1.04} & $0.50,2 \cdot 14$ & \multicolumn{2}{|c|}{0.96} & $0.42,2.18$ & 0.92 \\
\hline \multicolumn{10}{|l|}{ Women, all cases $(\mathrm{Nad} \geq 1)$} \\
\hline Folic acid intake $(\mu \mathrm{g} / \mathrm{d})$ & 202 & 35 & 280 & 20 & & 386 & 71 & & \\
\hline Cases $(n) / N$ & \multicolumn{2}{|c|}{$78 / 351$} & \multicolumn{2}{|c|}{$75 / 352$} & & \multicolumn{2}{|c|}{$73 / 352$} & & \\
\hline OR1 & \multicolumn{2}{|c|}{1.00} & \multicolumn{2}{|c|}{0.93} & $0.61,1.41$ & \multicolumn{2}{|c|}{0.91} & $0.57,1.45$ & 0.69 \\
\hline OR2 & \multicolumn{2}{|c|}{1.00} & \multicolumn{2}{|c|}{0.98} & $0.64,1.50$ & \multicolumn{2}{|c|}{0.83} & $0.50,1.37$ & 0.46 \\
\hline \multicolumn{10}{|c|}{ Men, single episode $(\mathrm{Nad}=1)$} \\
\hline Folic acid intake $(\mu \mathrm{g} / \mathrm{d})$ & 244 & 42 & 338 & 22 & & 445 & 70 & & \\
\hline Cases $(n) / N$ & \multicolumn{2}{|c|}{$15 / 259$} & \multicolumn{2}{|c|}{$15 / 260$} & & \multicolumn{2}{|c|}{$17 / 259$} & & \\
\hline OR1 & & & & & $0.47,2.45$ & & & $0.57,3.42$ & 0.46 \\
\hline Women, single episode ( & & & & & & & & & \\
\hline Folic acid intake $(\mu \mathrm{g} / \mathrm{d})$ & 201 & 35 & 279 & 21 & & 385 & 60 & & \\
\hline Cases $(n) / N$ & & & & & & & & & \\
\hline OR1 & & & & & $0.45,1.28$ & & & $0.50,1.64$ & 0.75 \\
\hline OR2 & & & & & $0.50,1.47$ & & & $0.49,1.69$ & 0.77 \\
\hline Men, recurrent episodes ( & $>1)$ & & & & & & & & \\
\hline Folic acid intake $(\mu \mathrm{g} / \mathrm{d})$ & 242 & 43 & 336 & 22 & & 441 & 69 & & \\
\hline Cases $(n) / N$ & & & & & & & & & \\
\hline OR1 & & & & & $0.22,1 \cdot 70$ & & & $0.06,0.98$ & 0.046 \\
\hline OR2 & & & & & $0.24,2.51$ & & & $0.05,1.25$ & 0.10 \\
\hline Women, recurrent episode & $\mathrm{ad}>1)$ & & & & & & & & \\
\hline Folic acid intake $(\mu \mathrm{g} / \mathrm{d})$ & 203 & 36 & 281 & 20 & & 386 & 72 & & \\
\hline Cases $(n) / N$ & & & & & & & & & \\
\hline OR1 & & & & & $0.77,2.56$ & & & $0.49,2.01$ & 0.93 \\
\hline OR2 & & & & & $0.69,2.51$ & & & $0.39,1.83$ & 0.63 \\
\hline
\end{tabular}

OR1, OR adjusted for age, intervention group (vitamin/mineral supplement or placebo), marital status (living alone or in couple), education level (three levels), socio-professional category (five categories) and total energy intake; OR2, OR for cases restricted to subjects with no depression history, adjusted as in OR1 model.

13-year follow-up than men with a folate intake above the median $^{(11)}$ : the association with folate intake appears much stronger for later occurrence of severe depression than for current depressive symptoms. In agreement with the study by Tolmunen et al. ${ }^{(11)}$, this study shows a strongly increased risk of recurrent depression in men with a low folate intake, whereas the risk of experiencing only one depressive episode was unchanged. Both studies suggest that a low folate intake is a risk factor mainly for severe or recurrent depression in men. There is no evident explanation for this observation. A possible hypothesis is that socio-demographic factors such as marital status and life events, strong determinants of first-episode depression, are not so, or much less, for recurrent depression, which tends to become independent of psycho-social circumstances $^{(26)}$. Biological factors could be more important for recurrences, including genetic factors, as also external influences such as diet and drugs. This difference between single-episode and recurrent depression could also explain why depressive symptoms measured cross-sectionally have not always been found to be associated with folate intake: only current symptoms are measured, not past episodes. Depression often reduces food intake or changes food choices, and it is possible that the association observed in cross-sectional studies between current depression and folate intake is, at least in part, a consequence of the effects of the depressive state on eating behaviour. However, this seems less likely in our study, and in another prospective study ${ }^{(11)}$, since food intake has been measured at the beginning of the follow-up, whereas depressive episodes were recorded throughout the whole follow-up. Moreover, the association we have observed was adjusted for total energy intake, thus taking food intake differences into account.

In cross-sectional studies, a high homocysteine plasma level has often been associated with depressive symptoms ${ }^{(6,9,27)}$, and homocysteine level has been found to increase with depression score in $\operatorname{men}^{(9)}$. In the SU.VI.MAX cohort, women have on average a higher folate status than men, and lower plasma levels of homocysteine ${ }^{(28)}$. Moreover, homocysteine level has been found to be inversely related to folate intake or status in men, but not in women ${ }^{(19)}$. Together, these results would suggest that the increased risk of depression due to a low folate intake could be mediated by an increased level of plasma homocysteine in men. This would also explain why the association between folate intake and recurrent depression has been observed only in men. However, this hypothesis is not in agreement with studies which found, on the contrary, an association of depressive symptoms with a low folate plasma level in women, but not in men ${ }^{(6,8)}$. Considering that depression rate is about twice as high in women as in men, further studies are needed to clarify the relations between folate, homocysteine, gender and depression in populations. 
In summary, this study suggests that a low folate intake increases the risk of recurrent depression, but not of singleepisode depression, in men. This association was not found in women. This study and other studies also suggest that recurrence and gravity are items of importance in the research of nutritional risk factors of depression, and that prospective studies allowing the recording of depressive episodes are especially needed for this purpose.

\section{References}

1. Eichholzer M, Tonz O \& Zimmermann R (2006) Folic acid: a public-health challenge. Lancet 367, 1352-1361.

2. Clarke R, Lewington S, Sherliker P \& Armitage J (2007) Effects of B-vitamins on plasma homocysteine concentrations and on risk of cardiovascular disease and dementia. Curr Opin Clin Nutr Metab Care 10, 32-39.

3. Reynolds E (2006) Vitamin B12, folic acid, and the nervous system. Lancet Neurol 5, 949-960.

4. Bottiglieri $\mathrm{T}$ (2005) Homocysteine and folate metabolism in depression. Prog Neuropsychopharmacol Biol Psychiatry 29, 1103-1112.

5. Coppen A \& Bolander-Gouaille C (2005) Treatment of depression: time to consider folic acid and vitamin B12. J Psychopharmacol 19, 59-65.

6. Bjelland I, Tell GS, Vollset SE, Refsum H \& Ueland PM (2003) Folate, vitamin B12, homocysteine, and the MTHFR 677C- $>$ T polymorphism in anxiety and depression: the Hordaland Homocysteine Study. Arch Gen Psychiatry 60, 618-626.

7. Morris MS, Fava M, Jacques PF, Selhub J \& Rosenberg IH (2003) Depression and folate status in the US Population. Psychother Psychosom 72, 80-87.

8. Ramos MI, Allen LH, Haan MN, Green R \& Miller JW (2004) Plasma folate concentrations are associated with depressive symptoms in elderly Latina women despite folic acid fortification. Am J Clin Nutr 80, 1024-1028.

9. Sachdev PS, Parslow RA, Lux O, Salonikas C, Wen W, Naidoo D, Christensen H \& Jorm AF (2005) Relationship of homocysteine, folic acid and vitamin B12 with depression in a middleaged community sample. Psychol Med 35, 529-538.

10. Tolmunen T, Voutilainen S, Hintikka J, Rissanen T, Tanskanen A, Viinamaki H, Kaplan GA \& Salonen JT (2003) Dietary folate and depressive symptoms are associated in middle-aged Finnish men. J Nutr 133, 3233-3236.

11. Tolmunen T, Hintikka J, Ruusunen A, Voutilainen S, Tanskanen A, Valkonen VP, Viinamaki H, Kaplan GA \& Salonen JT (2004) Dietary folate and the risk of depression in Finnish middle-aged men. A prospective follow-up study. Psychother Psychosom 73, $334-339$.
12. Hercberg S, Galan P, Preziosi P, Bertrais S, Mennen L, Malvy D, Roussel AM, Favier A \& Briancon S (2004) The SU.VI.MAX Study: a randomized, placebo-controlled trial of the health effects of antioxidant vitamins and minerals. Arch Intern Med 164, 2335-2342.

13. Mennen LI, Bertrais S, Galan P, Arnault N, Potier de Courcy G \& Hercberg S (2004) The use of computerised 24h dietary recalls in the French SU.VI.MAX Study: number of recalls required. Eur J Clin Nutr 56, 659-665.

14. Astorg P, Arnault N, Czernichow S, Noisette N, Galan P \& Hercberg S (2004) Dietary intakes and food sources of $n-6$ and $n-3$ PUFA in French adult men and women. Lipids 39, 527-535.

15. Arnault N, Astorg P, Aubert A, Bertrais S, et al. (2006) Table de composition des aliments SUVIMAX. Paris: Editions INSERM/ Economica.

16. Han YH, Yon M \& Hyun TH (2005) Folate intake estimated with an updated database and its association to blood folate and homocysteine in Korean college students. Eur J Clin Nutr 59, 246-254.

17. Serra-Majem L, Ribas-Barba L, Perez-Rodrigo C \& Bartrina JA (2006) Nutrient adequacy in Spanish children and adolescents. Br J Nutr 96, Suppl. 1, S49-S57.

18. Verkleij-Hagoort AC, de Vries JH, Stegers MP, Lindemans J, Ursem NT \& Steegers-Theunissen RP (2007) Validation of the assessment of folate and vitamin B12 intake in women of reproductive age: the method of triads. Eur J Clin Nutr 61, 610-615.

19. Mennen LI, de Courcy GP, Guilland JC, et al. (2002) Homocysteine, cardiovascular disease risk factors, and habitual diet in the French Supplementation with Antioxidant Vitamins and Minerals Study. Am J Clin Nutr 76, 1279-1289.

20. Kovess V (1996) The epidemiology of depression (In French). Encéphale 22, Spec No 1, 3-7.

21. Gasquet I, Nègre-Pagès L, Fourrier A, Nachbaur G, El Hasnaoui A, Kovess V \& Lépine JP (2005) Psychotropic drug use and mental psychiatric disorders in France; results of the general population ESEMeD/MHEDEA 2000 epidemiological study (In French). Encéphale 31, 195-206.

22. Lépine JP, Gastpar M, Mendlewicz J \& Tylee A (1997) Depression in the community: the first pan-European study DEPRES (Depression Research in European Society). Int Clin Psychopharmacol 12, 19-29.

23. Penninx BW, Guralnik JM, Ferrucci L, Fried LP, Allen RH \& Stabler SP (2000) Vitamin B(12) deficiency and depression in physically disabled older women: epidemiologic evidence from the Women's Health and Aging Study. Am J Psychiatry 157, 715-721.

24. Tiemeier H, van Tuijl HR, Hofman A, Meijer J, Kiliaan AJ \& Breteler MM (2002) Vitamin B12, folate, and homocysteine in depression: the Rotterdam Study. Am J Psychiatry 159, 2099-2101.

25. Miyake Y, Sasaki S, Tanaka K, Yokoyama T, Ohya Y, Fukushima W, Saito K, Ohfuji S, Kiyohara C \& Hirota Y (2006) Dietary folate and vitamins B12, B6, and B2 intake and the risk of postpartum depression in Japan: the Osaka Maternal and Child Health Study. J Affect Disord 96, 133-138.

26. Burcusa SL \& Iacono WG (2007) Risk for recurrence in depression. Clin Psychol Rev 27, 959-985.

27. Tolmunen T, Hintikka J, Voutilainen S, Ruusunen A, Alfthan G, Nyyssonen K, Viinamaki H, Kaplan GA \& Salonen JT (2004) Association between depressive symptoms and serum concentrations of homocysteine in men: a population study. Am J Clin Nutr 80, 1574-1578.

28. Chango A, Potier de Courcy G, et al. (2000) 5,10-methylenetetrahydrofolate reductase common mutations, folate status and plasma homocysteine in healthy French adults of the Supplementation en Vitamines et Mineraux Antioxydants (SU.VI.MAX) cohort. Br J Nutr 84, 891-896. 